\title{
Measurement of Local Myocardial Perfusion by Thermal Diffusion Microprobe during Coronary Artery Occlusion and Reperfusion in a Beating Canine Heart
}

\author{
Young Ho Jang, M.D., and Jin Mo Kim, M.D. \\ Department of Anesthesiology, School of Medicine, Keimyung University, Daegu, Korea
}

$=$ Abstract $=$

Background: The measurement of perfusion is very important to understand the physiology of the tissue level. The QFlow $^{\mathrm{TM}} 400$ perfusion measurement system is able to measure local tissue perfusion. The aim of this study was to validate thermal diffusion microprobe (TDM) in estimating myocardial blood flow during coronary artery occlusion and reperfusion in an animal beating heart model.

Methods: A total of 5 mongrel dogs were entered into the study. A left thoracotomy was performed under general anesthesia. After the left anterior descending coronary artery (LAD) was exposed, a TDM was inserted in the myocardium at the exposed LAD distributed area. The local myocardial perfusion was measured before, during and after LAD occlusion. To find the usefulness of TDM in a beating heart, $\mathrm{k}$ values were checked during the study. The $\mathrm{k}$ value or tissue conductivity should not exceed $6.23 \mathrm{~mW} / \mathrm{cm}^{\circ} \mathrm{C}$ in this system.

Results: All the $\mathrm{k}$ values were below $6.23 \mathrm{~mW} / \mathrm{cm}^{\circ} \mathrm{C}$ in this study. Baseline local myocardial perfusion was $52.0 \pm 18.3 \mathrm{ml} / \mathrm{min} / 100 \mathrm{~g}$. During LAD occlusion, the local myocardial perfusion was decreased to $18.4 \pm 12.0 \mathrm{ml} / \mathrm{min} / 100 \mathrm{~g}$. At 10,20 and 30 minutes after LAD reperfusion, the perfusion was recovered to $38.5 \pm 23.2,27.2 \pm 17.4$ and $36.2 \pm 17.2 \mathrm{ml} / \mathrm{min} / 100 \mathrm{~g}$, respectively, but the values at 20 and 30 minutes of reperfusion were significantly lower compared to baseline value.

Conclusions: We could use the QFlow $^{\mathrm{TM}} 400$ perfusion measurement system to measure myocardial injury produced by ischemia and subsequent reperfusion in a beating heart. With this system, we found that the local myocardial perfusion was not recovered to the baseline level in early state of the coronary reperfusion. (Korean J Anesthesiol 2002; 42: S 1 S 4)

Key Words: Coronary perfusion; ischemia/reperfusion; myocardial function.

\section{INTRODUCTION}

Perfusion is defined as the rate of replenishment of blood volume at the level of the capillary network. The

Received : November 14, 2001

Corresponding to : Young Ho Jang, Department of Anesthesiology, Dongsan Medical Center, 194 Dongsan-dong, Junggu, Daegu 700-712, Korea

Tel: 053-250-7193, Fax: 053-250-7240

E-mail: weonjo@dsmc.or.kr

The present research has been conducted by the Bisa Research Grant of Keimyung University in 2001 measurement of perfusion is very important to understand the physiology at the tissue level. The laser-Doppler flowmetry (LDF), radioactive microsphere and other techniques have been used to measure tissue perfusion so far. But the results using LDF are affected by hematocrit, erythrocyte velocity, tissue type, and etc. ${ }^{1)}$ The radioactive microsphere technique is suitable for animal models, but is not appropriate for clinical measurements. ${ }^{2)}$ The QFlow $^{\mathrm{TM}}$ 400 perfusion measurement system is designed by Thermal Technologies Corporation in USA to measure local tissue perfusion. This system, using thermal diffusion 
microprobe (TDM), is characterized by minimally invasive, continuous and real-time use. ${ }^{2)}$ There are several reports to validate the usefulness of this system. These validation studies were carried out in liver, brain, kidney, prostate and skin in human and animals. ${ }^{3-5)}$ But there is no data in beating heart with this system. Local tissue perfusion is disturbed during ischemia and reperfusion in organs. So we tried to validate the usefulness of QFlow $^{\mathrm{TM}}$ 400 perfusion measurement system in estimating local myocardial perfusion before and after coronary artery occlusion in an animal beating heart model.

\section{METHODS}

A total of 11 mongrel dogs, weighing $20-25 \mathrm{~kg}$, were entered into the study. The anesthesia was induced by 20 $\mathrm{mg} / \mathrm{kg}$ thiopental sodium and $0.2 \mathrm{mg} / \mathrm{kg}$ vecuronium bromide followed by tracheal intubation after 2 minutes. Mechanical ventilation was done with $50 \%$ nitrous oxide in oxygen and 1 vol\% enflurane with a tidal volume of $15 \mathrm{ml} / \mathrm{kg}$ and a respiratory rate of $12 / \mathrm{min}$.

A left thoracotomy was performed at the 5 th or 6 th intercostal space and left anterior descending coronary artery (LAD) was exposed for occlusion and release. A TDM (Thermal technologies Co., USA) was inserted in the myocardium perfused by the exposed LAD. For this technique, we used a 18 gauge angiocatheter. After the epicardium was punctured with angiocatheter, the TDM was advanced $1.5 \mathrm{~cm}$ length obliquely through the punctured site. To prevent the TDM displacement during cardiac contraction, the microprobe was sutured
To find the usefulness of TDM in beating heart, the $\mathrm{k}$ value were checked during the study. The $\mathrm{k}$ value or tissue conductivity should not exceed of $6.23 \mathrm{~mW} / \mathrm{cm}^{\circ} \mathrm{C}$ in this system. The $\mathrm{k}$ value exceeding $6.23 \mathrm{~mW} / \mathrm{cm}^{\circ} \mathrm{C}$ indicates inappropriate microprobe positioning or other artifacts.

After a sufficient stabilization period (20-30 minutes after surgical preparation), baseline local myocardial perfusion was measured. The exposed coronary artery was then occluded with a clip for a period of 15 minutes, and the perfusion was measured. The perfusion was also measured at 10, 20 and 30 minutes after LAD reperfusion. The average local myocardial perfusion values were calculated with 1 minute data at each measuring time. The amount of perfusion was presented as mean \pm SD. Statistical analysis of the data was performed by analysis of general lineal model (repeated measures) with SPSS program (version 10.0). Probability values $<0.05$ were considered significant.

\section{RESULTS}

In this study, we excluded 6 animals in the statistical analysis because they developed ventricular fibrillation immediately after reperfusion.

To find the usefulness of TDM in beating heart, the $\mathrm{k}$ value were checked. All the $\mathrm{k}$ values were below 6.23 $\mathrm{mW} / \mathrm{cm}^{\circ} \mathrm{C}$ in this study (Table 1 ).

The change in local myocardial perfusion during the LAD occlusion and reperfusion are presented in Fig. 1. Baseline local myocardial perfusion was $52.0 \pm 18.3 \mathrm{ml} /$ min/100 g. During LAD occlusion, the local myocardial

Table 1. The $\mathrm{k}$ Value in $\mathrm{QFlow}^{\mathrm{TM}} 400$ Perfusion Measurement System in Beating Canine Heart

\begin{tabular}{|c|c|c|c|c|c|}
\hline & \multirow{2}{*}{ Baseline } & \multirow{2}{*}{$\begin{array}{c}\text { During } \\
\text { LAD occlusion }\end{array}$} & \multicolumn{3}{|c|}{ After reperfusion (min) } \\
\hline & & & 10 & 20 & 30 \\
\hline $\begin{array}{c}\mathrm{k} \text { value } \\
\left(\mathrm{mW} / \mathrm{cm}^{\circ} \mathrm{C}\right)\end{array}$ & $5.76 \pm 0.21$ & $5.40 \pm 0.02$ & $6.21 \pm 0.07$ & $5.83 \pm 0.09$ & $5.67 \pm 0.02$ \\
\hline
\end{tabular}

Values are mean \pm SD. K: tissue conductivity value, LAD: left anterior descending coronary artery.

in place.

perfusion was decreased to $18.4 \pm 12.0 \mathrm{ml} / \mathrm{min} / 100 \mathrm{~g}$. All 


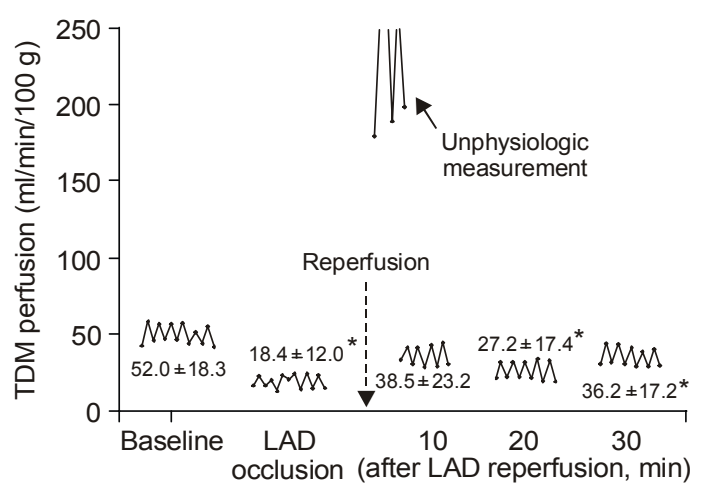

Fig. 1. Schematic presentation of local myocardial perfusion change during left anterior descending coronary artery (LAD) occlusion and reperfusion in beating canine heart. TDM: thermal diffusion microprobe. The numerics are mean \pm SD. *: $\mathrm{P}<0.05$, significantly different from the baseline.

6 dead animals had nearly $0 \mathrm{ml} / \mathrm{min} / 100 \mathrm{~g}$ perfusion during LAD occlusion.

In the immediate reperfusion period, the perfusion was abruptly increased to far over $250 \mathrm{ml} / \mathrm{min} / 100 \mathrm{~g}$ (the maximum range of QFlow $^{\mathrm{TM}} 400$ system is $250 \mathrm{ml} / \mathrm{min} / 100 \mathrm{~g}$ ) for 3 to 5 minutes (Fig. 1). At 10, 20 and 30 minutes after LAD reperfusion, the perfusion was recovered to $38.5 \pm$ $23.2,27.2 \pm 17.4$ and $36.2 \pm 17.2 \mathrm{ml} / \mathrm{min} / 100 \mathrm{~g}$, respectively, but the values at 20 and 30 minutes of reperfusion were significantly lower compared to baseline value.

\section{DISCUSSION}

Perfusion is a primary factor in the local transport of heat, nutrients, drugs, oxygen and waste products. It means that the key determinant of tissue oxygenation and substrate delivery is tissue perfusion. So the ability to measure tissue perfusion is a key point to the understand both normal and pathologic physiology.

Many techniques, such as LDF and radioactive microsphere method have been developed to measure tissue blood flow. ${ }^{6-8)}$ The LDF uses the erythrocyte velocity by doppler and the signal depends on the hematocrit, erythrocyte velocity, vascular geometry, etc. ${ }^{2)}$ The radioactive microsphere technique is suitable for animal models, but is not appropriate for clinical measurements.

Many authors have tried to evaluate myocardial function. Most studies used hemodynamics, blood flow, myocardial oxygen tension, and requirement of antihypertensive drugs as parameters for myocardial function. ${ }^{9-12)}$

But they did not measure local myocardial perfusion directly. In this study, we used TDM in QFlow $^{\mathrm{TM}} 400$ perfusion measurement system which was designed by thermal technologies corporation to measure local tissue perfusion. This TDM has been devised for the sensitive, continuous, minimally invasive, and real-time monitoring of local tissue perfusion. Several studies have validated the usefulness of this system to measure local tissue perfusion. ${ }^{1,3-5)}$ This system is simple, repeatable and provides real-time simultaneous perfusion. The accuracy of perfusion with this system is highly dependent on proper placement of microprobe, and on maintenance of proper placement against motion disturbance. There have been no studies using this system in beating heart models so far. So we first tried to validate the usefulness of this system with $\mathrm{k}$ value in beating animal heart. Since tissue contains water, protein and fat, tissue conductivity ( $\mathrm{k}$ value) can not exceed that of water $\left(6.23 \mathrm{~mW} / \mathrm{cm}^{\circ} \mathrm{C}\right)$. Therefore, the $\mathrm{k}$ value over $6.23 \mathrm{~mW} / \mathrm{cm}^{\circ} \mathrm{C}$ may indicate inappropriate microprobe positioning ${ }^{2)}$ and the perfusion value may be inappropriate. In this study, all $\mathrm{k}$ values before and after LAD occlusion were below $6.23 \mathrm{~mW} / \mathrm{cm}^{\circ} \mathrm{C}$. The baseline local myocardial perfusion measured by QFlow $^{\mathrm{TM}} 400$ perfusion measurement system was $52.0 \pm 18.3 \mathrm{ml} / \mathrm{min} / 100 \mathrm{~g}$.

The perfusion during LAD occlusion was decreased to $35 \%$ of baseline value. This result may indicate that collaterals from other conduit coronary arteries, such as right coronary and circumflex artery, supply some area of LAD territory despite of the LAD occlusion. But 6 dead animals had nearly $0 \mathrm{ml} / \mathrm{min} / 100 \mathrm{~g}$ perfusion value and developed ventricular fibrillation immediately after reperfusion.

The local myocardial perfusion was abruptly increased up to 250 and $\mathrm{more} \mathrm{ml} / \mathrm{min} / 100 \mathrm{~g}$ immediately after LAD reperfusion. The duration of this state was about 3-5 minutes. In this period, the QFlow ${ }^{\mathrm{TM}} 400$ perfusion measurement system could not measure the perfusion value 
(unphysiologic measurement). We think that the reason for this is due to the hyperemic state after reperfusion.

One of the interesting results in this study was that the local myocardial perfusion was not recovered to the baseline level for quite a while after LAD reperfusion.

This phenomenon may have resulted from the impaired microcirculation distal to the LAD distributed area during immediate reperfusion period. Many substances such as free radical, cytokine, prostaglandins, and other peptides may play a role in this mechanism. ${ }^{1)}$ So the local tissue perfusion change may be a very important and reliable parameter in ischemia or reperfusion state when we need to consider the reperfusion injury.

In conclusion, even though the measurement of perfusion was impossible in hyperemic state just after reperfusion, we could use $\mathrm{QFlow}^{\mathrm{TM}} 400$ perfusion measurement system to measure myocardial perfusion during ischemia and subsequent reperfusion in a beating heart. With this system, we could find that the local myocardial perfusion was not recovered to the baseline level in early state of the coronary reperfusion.

\section{ACKNOWLEDGMENTS}

We are grateful to Martin GT, Ph. D. and Bowman HF, $\mathrm{Ph}$. D. in Harvard-MIT Biochemical Engineering Center, MIT Cambridge MA, and Hemedex Inc. for technical advice of TD technology. Also we are grateful to MediLux Inc. for assistance in data analysis.

\section{REFERENCES}

1. Smits GJ, Roman RJ, Lombard JH: Evaluation of a laser-Doppler flowmetry as a measure of tissue blood flow. Appl Physiol 1986; 61: 666-72.

2. Martin GT, Bowman HF: Validation of real-time continuous perfusion measurement. Med Biol Eng \& Comput 2000; 38: 319-25.
3. Klar E, Kraus T, Bleyl J, Newman WH, Bowman HF, Hofmann WJ, et al: Thermodiffusion for continuous quantification of hepatic microcirculation-Validation and potential in liver transplantation. Microvasc Res 1999; 58: 156-66.

4. Vajkoczy P, Roth H, Horn P, Lucke T, Thome C, Hubner U, et al: Continuous monitoring of regional cerebral blood flow: experimental and clinical validation of a novel thermal diffusion microprobe. J Neurosurg 2000; 93: 265-74.

5. Kraus T, Klar E, Osswald BR, Fernandes L, Mehrabi A, Gebhard MM, et al: Continuous measurement of porcine renal cortex microcirculation with enhanced thermal diffusion technology. J Surg Res 1996; 61: 531-6.

6. Almond NE, Wheatley AN: Measurement of hepatic perfusion in rats by laser Doppler flowmetry. Am J Physiol 1992; 262: G203-9.

7. Arvisddon D, Svensson H, Hanglund U: Laser-Doppler flowmetry for estimating liver blood flow. Am J Physiol 1988; 254: G471-6.

8. Kim YI, Kai T, Kawano T, Goto S, Kodama Y, Yasunaga $F$, et al: Predictive value of liver tissue flow in assessment of the viability of liver grafts after extended preservation in pigs. Transplant 1992; 5: 382-7.

9. Vecht RJ, Swanson KT, Nicolaides EP, Lennox SC, Gibson DG: Comparison of intravenous nicardipine and nitroglycerin to control systemic hypertension after coronary artery bypass grafting. Am J Cardiol 1989; 64: H19-21.

10. Lambert CR, Pepine CJ: Effects of intravenous and intracoronary nicardipine. Am J Cardiol 1989; 64: H815.

11. Hashimoto H, Asano M, Takiguchi Y, Katoh H, Nakashima M: Effects of nicardipine, a dihydropyridine calcium antagonist, on regional myocardial blood flow, myocardial oxygen tension, and electrical abnormalities during acute coronary artery occlusion in dogs. J Cardiovasc Pharmacol 1985; 7: 613-21.

12. Apostolidou IA, Despotis GJ, Hogue CW, Skubas NJ, McCawley CA, Hauptmann EL, et al: Antiischemic effects of nicardipine and nitroglycerin after coronary artery bypass grafting. Ann Thorac Surg 1999; 67: 417-22. 